Check for updates

Cite this: RSC Adv., 2019, 9, 35045

Received 3rd August 2019

Accepted 27th September 2019

DOI: 10.1039/c9ra06023e

rsc.li/rsc-advances

\section{A germanium and zinc chalcogenide as an anode for a high-capacity and long cycle life lithium battery $\uparrow$}

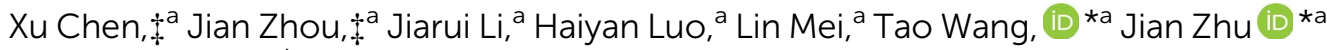 \\ and Yong Zhang ${ }^{\star b}$
}

\begin{abstract}
High-performance lithium ion batteries are ideal energy storage devices for both grid-scale and large-scale applications. Germanium, possessing a high theoretical capacity, is a promising anode material for lithium ion batteries, but still faces poor cyclability due to huge volume changes during the lithium alloying/ dealloying process. Herein, we synthesized an amorphous germanium and zinc chalcogenide (GZC) with a hierarchically porous structure via a solvothermal reaction. As an anode material in a lithium ion battery, the GZC electrode exhibits a high reversible capacity of $747 \mathrm{~mA} \mathrm{~h} \mathrm{~g}^{-1}$ after 350 cycles at a current density of $100 \mathrm{~mA} \mathrm{~g}^{-1}$ and a stable capacity of $370 \mathrm{~mA} \mathrm{~h} \mathrm{~g}^{-1}$ after 500 cycles at a current density of $1000 \mathrm{~mA} \mathrm{~g}^{-1}$ along with $92 \%$ capacity retention. All of these outstanding electrochemical properties are attributed to the hierarchically porous structure of the electrode that has a large surface area, fast ion conductivity and superior structural stability, which buffers the volumetric variation during charge/discharge processes and also makes it easier for the electrolyte to soak in, affording more electrochemically active sites.
\end{abstract}

\section{Introduction}

Over the last few decades, lithium ion batteries (LIBs) have been proposed as a promising type of energy storage device for application in portable electronic equipment and smart grids..$^{1-5}$ However, the currently available LIBs with graphitic carbon as the anode material cannot satisfy the continuously increasing requirements of electric vehicles and large-scale energy storage applications. ${ }^{6,7}$ To meet the growing power-supply demand, tremendous efforts have been made to develop LIBs with high energy density and long-lasting cycle performance.

Germanium, as a homologue of carbon with similar redox chemistry, is considered as an alternative, with a great foreground development, to commercial carbon materials for LIBs. Compared with commercial carbon materials $\left(370 \mathrm{~mA} \mathrm{~h} \mathrm{~g}{ }^{-1}\right)$, Ge has a higher theoretical capacity $\left(1624 \mathrm{~mA} \mathrm{~h} \mathrm{~g}{ }^{-1}\right.$ for $\mathrm{Li}_{22} \mathrm{Ge}_{5}$ and $1384 \mathrm{~mA} \mathrm{~h} \mathrm{~g}^{-1}$ for $\mathrm{Li}_{15} \mathrm{Ge}$ ). ${ }^{8,9}$ In addition, Ge has other unique properties, such as a faster $\mathrm{Li}^{+}$diffusion rate (400 times faster than $\mathrm{Si}$ ), and superior conductivity (100 times greater than that of Si)..$^{10,11}$ Due to these advantages, Ge-based materials

\footnotetext{
${ }^{a}$ State Key Laboratory for Chemo/Biosensing and Chemometrics, College of Chemistry Institution, Hunan University, Changsha 410082, China.E-mail: jzhu@hnu.edu.cn ${ }^{b}$ Fujian Provincial Key Laboratory of Functional Materials and Applications, Xiamen University of Technology, Xiamen 361024, China

$\dagger$ Electronic supplementary information (ESI) available. See DOI: 10.1039/c9ra06023e

$\ddagger$ These authors contributed equally to this work.
}

have attracted more and more attention in recent years. Nevertheless, Ge-based materials have been suffering from poor cyclability in the process of becoming commercialized anode materials. During lithium alloying/dealloying reactions, devastating expansion and contraction take place inside the electrode, which leads to the pulverization of the electrode material and eventual decay of the performance of the battery. ${ }^{12,13}$ Numerous strategies have been applied to alleviate the volume change and improve the electrochemical properties, including nanosizing the Ge particles, ${ }^{14-16}$ modifying the surface by coating, ${ }^{16,17}$ doping with other elements ${ }^{18-20}$ and introducing a porous structure. ${ }^{21,22}$ All of these methods have partially improved the electrochemical performance of Ge-based electrode materials and can be categorised into two approaches: changing the component or shaping an efficacious structure and morphology.

Among those strategies, a number of papers have reported that germanium chalcogenide anode materials, such as binary sulfides and especially ternary sulfides, exhibit a great cycling performance. ${ }^{13,23-25}$ In terms of the components, the use of sulfur compounds could mitigate the volume-change stress by forming an in situ $\mathrm{Li}_{2} \mathrm{~S}$ inert matrix. It is suggested that compounds such as GeS and $\mathrm{GeS}_{2}$ are irreversibly converted to Ge in the first cycle: $\mathrm{GeS}+2 \mathrm{Li}^{+}+2 \mathrm{e}^{-} \rightarrow \mathrm{Ge}+\mathrm{Li}_{2} \mathrm{~S} .{ }^{15} \mathrm{Ge}$ as the active material can then efficiently store and release $\mathrm{Li}^{+}$ according to the reversible alloying and dealloying reaction: $\mathrm{Ge}$ $+x \mathrm{Li}^{+}+x \mathrm{e}^{-} \rightarrow 4 \mathrm{Li}_{x} \mathrm{Ge}(0 \leq x \leq 4.4)$; during this process $\mathrm{Li}_{2} \mathrm{~S}$ surrounding Ge acts as a buffer, thus retarding the volume 
change. Moreover, compared with their binary counterparts, ternary germanium chalcogenides form an anode that exhibits a better electrochemical performance for LIBs. ${ }^{24,25}$ The introduction of another metal like $\mathrm{Zn}$, which is also an electrochemically active species, can also accommodate the volume change during the charge/discharge process thus leading to long-term cycling stability. ${ }^{\mathbf{2 6 - 2 8}}$

Herein, we report on a germanium and zinc chalcogenide (GZC) and have investigated the electrochemical performance of the GZC electrode for the first time. The GZC with its hierarchically porous structure and fast ion conductivity not only offers sufficient space to overcome the damage caused by the volume expansion of active materials during charge and discharge processes, but also provides highly efficient channels for the fast transport of lithium ions and abundant electrochemically active sites to achieve higher reversible capacity. Thus, the unique structural design affords outstanding battery performance $\left(747 \mathrm{~mA} \mathrm{~h} \mathrm{~g}^{-1}\right.$ at a current density of $100 \mathrm{~mA} \mathrm{~g}^{-1}$ over 350 cycles and $370 \mathrm{~mA} \mathrm{~h} \mathrm{~g} \mathrm{~g}^{-1}$ at a high current density of $1000 \mathrm{~mA} \mathrm{~g}^{-1}$ after 500 continuous cycles), establishing this novel electrode as a very promising prospect in the field of highcapacity and long-life energy storage.

\section{Experimental}

\subsection{Synthesis of GZC-120-ZnGeS}

The solvothermal synthesis of GZC-120-ZnGeS is described elsewhere. ${ }^{29}$ First, powdered Ge $(0.089 \mathrm{~g}, 1.23 \mathrm{mmol})$, $\mathrm{Zn}\left(\mathrm{NO}_{3}\right)_{2} \cdot 6 \mathrm{H}_{2} \mathrm{O}(0.089 \mathrm{~g}, 0.30 \mathrm{mmol})$, and sulfur (S, $0.220 \mathrm{~g}, 6.88$ $\mathrm{mmol})$ were dispersed in $\mathrm{N}$-(2-aminoethyl)morpholine (AEM, $2.5 \mathrm{~mL}$ ) solution. After stirring for approximately $30 \mathrm{~min}$, the mixture was transferred and sealed into a Teflon-lined stainlesssteel autoclave with a $23 \mathrm{~mL}$ inner volume. The container was then heated at $190{ }^{\circ} \mathrm{C}$ in an electric oven. 12 days later, large light-yellow rhombic dodecahedral crystals of GZC-120-ZnGeS were finally obtained.

\subsection{Materials characterization}

Scanning electron microscopy (SEM, Zeiss, Germany) and transmission electron microscopy (TEM, FEI Tecnai G2 F20, operating at $200 \mathrm{kV}$, America) were used to investigate the microstructural morphology of the GZC material. All of the BET surface area tests were carried out using a Micromeritics ASAP 2020 HD88 system (Mack, America). The surface characteristics of the samples were investigated via X-ray photoelectron spectroscopy (XPS, Surface Analysis PHI5600, Physical Electronics).

\subsection{Electrochemical measurements}

The electrochemical characterization of the material was carried out using coin cells (CR2032) assembled in an argonfilled glove box, with Li metal as the counter/reference electrode, and $1 \mathrm{M} \mathrm{LiPF}_{6}$ in EC-DEC solution (ethylene carbonate and diethyl carbonate, $1: 1$ volumetric ratio) as the electrolyte. The working electrode was prepared by casting the slurry onto a copper foil and then drying at $70{ }^{\circ} \mathrm{C}$ for $12 \mathrm{~h}$ under vacuum. Typically, the slurry was a mixture of active material, acetylene black and sodium carboxymethyl cellulose (CMC) with a weight ratio of $6: 3: 1$. The mass loading of active material was approximately $0.5 \mathrm{mg}$. The process of galvanostatic charge/ discharge was measured using Arbin Instruments BT 2000 apparatus. An electrochemical workstation was used to conduct the cyclic voltammetry (CV) and electrochemical impedance spectroscopy (EIS) tests.

\section{Results and discussion}

Fig. 1 displays the microstructure and general morphology of the GZC via SEM and TEM. Fig. 1a is a low magnification SEM image, showing that the GZC consists of a large number of thin sheets with a film size ranging from 1 to $10 \mu \mathrm{m}$. Fig. $1 \mathrm{~b}$ and $\mathrm{c}$ indicate the typical nanosheet morphology of the GZC. This unique $2 \mathrm{D}$ structure is due to the combined effect of temperature and barometric pressure of thermal transformation. The thin sheet structure and ordered porous structure can be observed much more clearly by TEM in Fig. 1d and e, respectively. As an anode material for LIBs, this hierarchical structure could provide highly efficient ion transporting channels and adequate free space to tolerate the volumetric change during cycles. $^{30}$ The inset in Fig. If shows the electron diffraction pattern, further confirming that GZC has no crystal lattice and is amorphous.

As is known, to some extent the size and structure of pores can determine the electrochemical properties of an electrode material. ${ }^{31}$ Therefore, nitrogen adsorption and desorption isotherms were used to evaluate the surface area and pore size distribution of the GZC. Fig. 2a shows the $\mathrm{N}_{2}$ adsorption and desorption isotherms for the GZC. It is obvious that the quantity of $\mathrm{N}_{2}$ adsorbed representing the pore volume gradually increases until the relative pressure reaches 0.9 . Referring to the relevant literature, this is the characteristic of Type III adsorption isotherms, ${ }^{32,33}$ which confirms the existence of some macropores as shown in Fig. $2 \mathrm{~b}$ and the multilayer formation shown in the SEM and TEM images in Fig. 1. In addition, the calculated Brunauer-Emmett-Teller (BET) specific surface area of the GZC

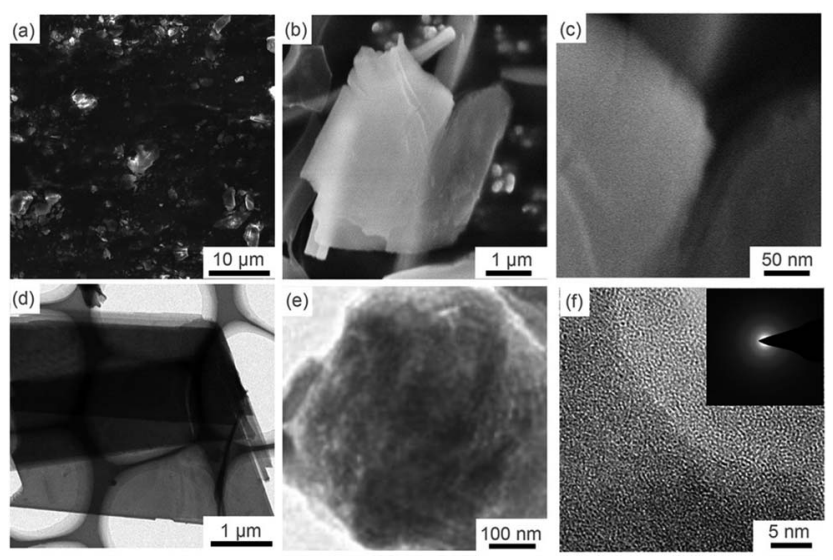

Fig. 1 Morphological characterization of the GZC: SEM images of the GZC at different magnifications $(a-c)$ and TEM images of the GZC at different magnifications $(d-f)$. 

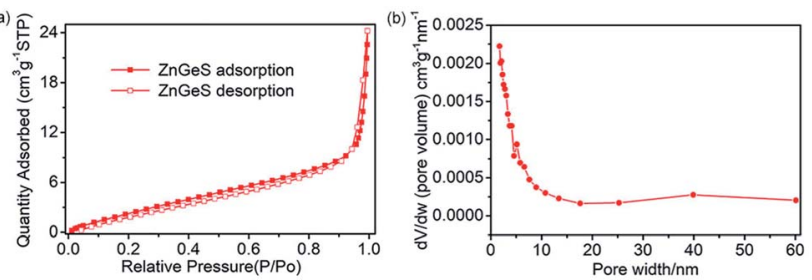

Fig. 2 (a) $\mathrm{N}_{2}$ adsorption and desorption isotherms, (b) pore size distribution of the GZC

is approximately $12.6043 \mathrm{~m}^{2} \mathrm{~g}^{-1}$. The presentation of the pore distribution in Fig. $2 \mathrm{~b}$ reveals that the pore size mainly distributes in the range of $0-6 \mathrm{~nm}$, suggesting most of the pores belong to the micropore $(<2 \mathrm{~nm})$ and mesopore $(2-8 \mathrm{~nm})$ classes. We also collected the XPS results from the surface of the sample (Fig. S1 in the ESI $\dagger$ ), which show the valence state of Ge, $\mathrm{S}$ and $\mathrm{Zn}$, along with the atomic ratios of $\mathrm{C}, \mathrm{N}, \mathrm{O}, \mathrm{S}, \mathrm{Zn}$ and Ge elements in the GZC composite.

As an anode material, the electrochemical performance of the GZC was researched using half-cells with Li foils as counter electrodes. Fig. 3a demonstrates the charge and discharge voltage profiles of the GZC at the current density of $1000 \mathrm{~mA} \mathrm{~g}^{-1}$ for $1,2,5,100,200$ and 350 cycles in the voltage range of $0.01-$ $3.0 \mathrm{~V}\left(v s . \mathrm{Li} / \mathrm{Li}^{+}\right)$. Correspondingly, the first five cyclic voltammetry (CV) curves of the GZC electrode at a scan rate of $0.1 \mathrm{mV}$ $\mathrm{s}^{-1}$ in the voltage window of $0.01-3.0 \mathrm{~V}\left(v s . \mathrm{Li} / \mathrm{Li}^{+}\right)$are presented in Fig. 3b. The first discharge and charge capacities are 899.6

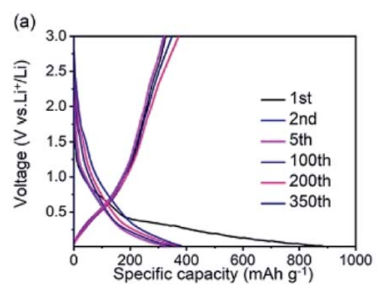

(c)

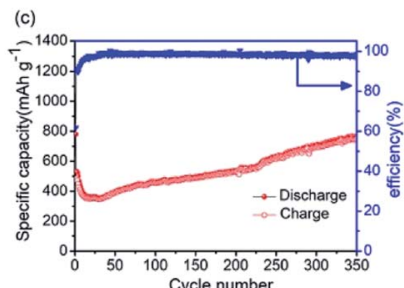

(e)

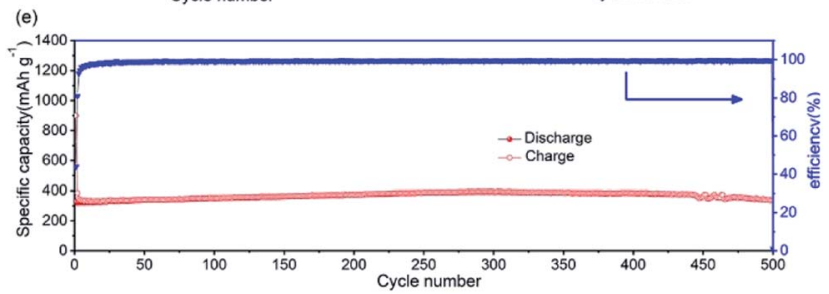

Fig. 3 (a) Charge and discharge voltage profiles of the GZC at $1 \mathrm{~A} \mathrm{~g}^{-1}$. (b) Cyclic voltammetry curves of the GZC tested between $0.01-3 \mathrm{~V}$ at a scan rate of $0.1 \mathrm{mV} \mathrm{s}^{-1}$. (c) Cycling performance of the GZC at $100 \mathrm{~mA} \mathrm{~g}^{-1}$. (d) Rate capabilities of the GZC electrodes at current densities from 0.1 to $1 \mathrm{~A} \mathrm{~g}^{-1}$. (e) Long-term cycling performance of the GZC at a high current density of $1 \mathrm{~A} \mathrm{~g}^{-1}$. and $326.7 \mathrm{~mA} \mathrm{~h} \mathrm{~g}^{-1}$, respectively, with an initial coulombic efficiency of $43.9 \%$, indicating a high irreversible reaction in the first cycle. The reason for the high initial capacity loss is the formation of the solid electrolyte interface (SEI) layer and the decomposition of electrolyte. ${ }^{34}$ After the first four cycles, the battery began to maintain stability with a capacity levelling at approximately $350 \mathrm{~mA} \mathrm{~h} \mathrm{~g}{ }^{-1}$ and a coulombic efficiency approaching $100 \%$ up to 400 cycles. During the initial cathodic scan, three small reduction peaks can be observed. The small peak appearing at $0.51 \mathrm{~V}$ which disappeared from the second cycle is attributed to the decomposition of the GZC. ${ }^{35}$ The presence of another three reduction peaks at $0.56,1.13$ and $1.52 \mathrm{~V}$ after the first cycle could originate from multistep alloying of $\mathrm{Li}_{x} \mathrm{Ge}$ and $\mathrm{Li}_{x} \mathrm{Zn}$. The anodic peak at $2.30 \mathrm{~V}$ which does not appear in the first cycle is deduced to represent reversible reactions such as: $\mathrm{ZnS}+2 \mathrm{Li}^{+}+2 \mathrm{e}^{-} \leftrightarrow \mathrm{Zn}+\mathrm{Li}_{2} \mathrm{~S}$ (and $\left.\mathrm{GeS}_{2}+4 \mathrm{Li}^{+}+4 \mathrm{e}^{-} \leftrightarrow \mathrm{Ge}+2 \mathrm{Li}_{2} \mathrm{~S}\right)$. Other peaks at $1.83 \mathrm{~V}$ and $0.5 \mathrm{~V}$ are ascribed to the process of $\mathrm{Li}_{x} \mathrm{Ge}$ and $\mathrm{Li}_{x} \mathrm{Zn}$ dealloying into $\mathrm{Ge}$ and $\mathrm{Zn}$, respectively. The $\mathrm{CV}$ curves almost overlap after the first cycle, revealing that the GZC anode has an excellent reversibility and electrochemical stability. Unlike many other LIBs, the capacity of which could possibly degrade constantly after the first cycle, as shown in Fig. 3c, the specific capacity of the GZC electrode unexpectedly increased after the first 30 cycles $\left(346 \mathrm{~mA} \mathrm{~h} \mathrm{~g}^{-1}\right)$ up to 350 cycles $\left(747 \mathrm{~mA} \mathrm{~h} \mathrm{~g}^{-1}\right)$. This result may be attributed to gradually increased resistance and permeation of the electrolyte into the internal area of the electrode material. To prove this statement, we also carried out electrochemical impedance spectroscopy (EIS) of the GZC electrode as shown in Fig. $\mathrm{S} 2 ; \dagger$ the charge transfer resistance $\left(R_{\mathrm{ct}}\right)$ is gradually increased after the first cycle, which is consistent with the loss of capacity over the first 30 cycles. Afterwards, the $R_{\mathrm{ct}}$ began to decrease which correlated well with the enhanced capacity. We can reasonably speculate that a process took place where the electrolyte gradually permeated into the internal area of the electrode material and activated it continuously. In addition, the average capacity from the 1st cycle to the 350th reached $534 \mathrm{~mA} \mathrm{~h} \mathrm{~g}{ }^{-1}$, which is a comparably high capacity, with an average coulombic efficiency of approximately $98 \%$.

The rate performance from 0.1 to $1 \mathrm{~A} \mathrm{~g}^{-1}$ is presented in Fig. 3d. At current densities of $0.1,0.2,0.5$ and $1 \mathrm{~A} \mathrm{~g}^{-1}$, the GZC electrode exhibits specific capacities of $716,580,456$ and $335 \mathrm{~mA} \mathrm{~h} \mathrm{~g}^{-1}$, respectively. More importantly, when the current density returned back to $0.1 \mathrm{~A} \mathrm{~g} \mathrm{~g}^{-1}$, the GZC still retained a specific capacity of $692 \mathrm{~mA} \mathrm{~h} \mathrm{~g}{ }^{-1}$ with only $3 \%$ capacity degradation, signifying the fast reaction kinetics and exceptional stability of the GZC electrode.

In order to further explore the long-term cycling performance of the GZC electrode, galvanostatic charge and discharge measurements at a current density of $1 \mathrm{~A} \mathrm{~g}^{-1}$ were carried out. As displayed in Fig. 3e, it exhibits a high capacity of $352 \mathrm{~mA} \mathrm{~h} \mathrm{~g}^{-1}$ at the 100 th cycle and $337 \mathrm{~mA} \mathrm{~h} \mathrm{~g}^{-1}$ at the 500th cycle with a capacity retention of $96 \%$, which indicates an exceedingly good cycling performance compared with previous reports regarding the use of Ge-based material as electrodes. The terrific cycling performance could be attributed to the advantages of the distinctive structural design of the GZC 

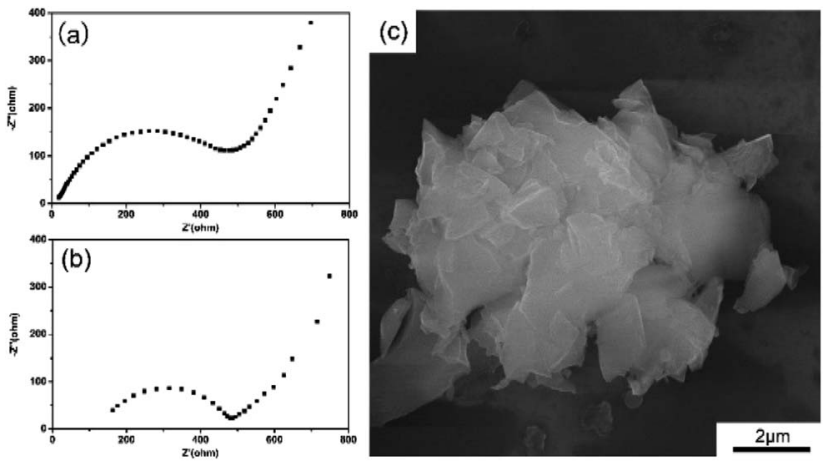

Fig. 4 (a) Nyquist plot of the GZC electrode in the fresh state. (b) Nyquist plot of the GZC electrode after 600 cycles. (c) SEM image of the GZC after 1000 charge-discharge cycles.

provides. Firstly, the hierarchically porous structure with superior structural stability possesses sufficient void space throughout the whole electrode, allowing the active electrode to expand freely without rupturing the whole electrode structure, thereby achieving excellent cycling stability. Moreover, the porous design with its mesoporous and microporous structure offers highly efficient channels for the fast transport of lithium ions during cycling, resulting in continuous high capacity.

Fig. 4a and b exhibit the Nyquist plots of the GZC electrode before cycling and after 600 cycles, respectively. It is obvious that in each graph there is a semicircle in the high-frequency region and a straight line in the low-frequency region. The diameter of the semicircle is related to the $R_{\mathrm{ct}}$, the increase in which is the main cause of the loss of capacity. ${ }^{36}$ It is apparent that the $R_{\mathrm{ct}}$ value of the initial cell is much lower than that after cycling, which is consistent with the outstanding cycling performance of the GZC electrode. Finally, a half-cell applying the GZC as the anode material was disassembled after 1000 cycles at $1 \mathrm{~A} \mathrm{~g}^{-1}$ so that the morphology change after repetitive charge and discharge processes could be investigated. The cell was disassembled in an Ar-filled glove box, washed with dimethyl carbon (DMC) three times and dried for $12 \mathrm{~h}$ before SEM examination. As Fig. 4c shows, the nanosheet structure of the GZC is still maintained overall and no obvious pulverization could be observed, demonstrating the good structural stability of the GZC material.

\section{Conclusions}

In conclusion, a novel GZC electrode was synthesized via a solvothermal reaction. The morphology, structure and electrochemical properties were investigated. The hierarchical structure design with high structural stability not only provides efficient channels for the fast transport of lithium ions and more electrochemical active sites, but also relieves volume expansion during cycling, thus achieving continuous high reversible capacity and outstanding cycling stability. Consequently, as an anode material for LIBs, it exhibits a high reversible capacity of $747 \mathrm{~mA} \mathrm{~h} \mathrm{~g}^{-1}$ after 350 cycles at a current density of $100 \mathrm{~mA} \mathrm{~g}^{-1}$ and a high specific capacity of
$370 \mathrm{~mA} \mathrm{~h} \mathrm{~g}{ }^{-1}$ at a current density of $1000 \mathrm{~mA} \mathrm{~g}^{-1}$ with $92 \%$ capacity retention after 500 cycles. The excellent electrochemical performance indicates great application prospects in the field of future energy storage devices.

\section{Conflicts of interest}

There are no conflicts to declare.

\section{Acknowledgements}

This work was financially supported by the National Natural Science Foundation of China (No. 21805076).

\section{References}

1 M. Li, J. Lu, Z. Chen and K. Amine, Adv. Mater., 2018, 30, 1800561.

2 J. W. Choi and D. Aurbach, Nat. Rev. Mater., 2016, 1, 16013. 3 J. Lu, Z. Chen, F. Pan, Y. Cui and K. Amine, Electrochem. Energy Rev., 2018, 1, 35-53.

4 T. Kim, W. Song, D. Y. Son, K. O. Luis and Y. Qi, J. Mater. Chem. A, 2019, 7, 2942-2964.

5 S. Ni, J. Liu, D. Chao and L. Mai, Adv. Energy Mater., 2019, 9, 1803324.

6 T. Wang, J. Zhu, Z. Wei, H. Yang, Z. Ma, R. Ma, J. Zhou, Y. Yang, L. Peng, H. Fei, B. Lu and X. Duan, Nano Lett., 2019, 19, 4384-4390.

7 P. Albertus, S. Babinec, S. Litzelman and A. Newman, Nat. Energy, 2017, 3, 16-21.

8 Q. Zhang, H. Chen, L. Luo, B. Zhao, H. Luo, X. Han, J. Wang, C. Wang, Y. Yang, T. Zhu and M. Liu, Energy Environ. Sci., 2018, 11, 669-681.

9 S. Wu, C. Han, J. Iocozzia, M. Lu, R. Ge, R. Xu and Z. Lin, Angew. Chem., Int. Ed., 2016, 55, 7898-7922.

10 H. Tian, F. Xin, X. Wang, W. He and W. Han, J. Mater., 2015, 1, 153-169.

11 T. Kennedy, M. Brandon and K. M. Ryan, Adv. Mater., 2016, 28, 5696-5704.

12 H. Jung, P. K. Allan, Y. Y. Hu, O. J. Borkiewicz, X. L. Wang, W. Q. Han, L. S. Du, C. J. Pickard, P. J. Chupas, K. W. Chapman, A. J. Morris and C. P. Grey, Chem. Mater., 2015, 27, 1031-1041.

13 C. Yang, Y. Jiang, X. Liu, X. Zhong and Y. Yu, J. Mater. Chem. A, 2016, 4, 18711-18716.

14 L. Xin, L. Yu-Si, M. M. Harris, L. Jihao, W. Kai-Xue and C. JieSheng, Chem. Eng. J., 2018, 354, 616-622.

15 X. Xiao, X. Li, S. Zheng, J. Shao, H. Xue and H. Pang, Adv. Mater. Interfaces, 2017, 4, 1600798.

16 D. Li, H. Wang, H. K. Liu and Z. Guo, Adv. Energy Mater., 2016, 6, 1501666.

17 B. Wang, Z. Wen, J. Jin, X. Hong, S. Zhang and K. Rui, J. Power Sources, 2017, 342, 521-528.

18 W. Cai, J. Zhou, G. Li, K. Zhang and Y. Qian, ACS Appl. Mater. Interfaces, 2016, 8, 27679-27687. 
19 Y. Fang, R. Liu, L. Zeng, J. Liu, L. Xu, X. He, B. Huang, Q. Chen, M. Wei and Q. Qian, Electrochim. Acta, 2019, 318, 737-774.

20 K. Jin, X. Zhou, L. Zhang, X. Xin, G. Wang and Z. Liu, J. Phys. Chem. C, 2013, 117, 21112-21119.

21 G. K. Sung and C. M. Park, J. Mater. Chem. A, 2017, 5, 56855689.

22 D. Li, H. Wang, T. Zhou, W. Zhang, H. K. Liu and Z. Guo, Adv. Energy Mater., 2017, 7, 1700488.

23 T. Kennedy, E. Mullane, H. Geaney, M. Osiak, C. O'Dwyer and K. M. Ryan, Nano Lett., 2014, 14, 716-723.

24 L. Fu, C. Zhang, B. Chen, Z. Zhang, X. Wang and J. Zhao, Inorg. Chem. Front., 2017, 4, 541-546.

25 X. Y. Yu and X. W. Lou, Adv. Energy Mater., 2018, 8, 1701592. 26 Y. R. Lim, C. S. Jung, H. S. Im, K. Park, J. Park, W. I. Cho and E. H. Cha, J. Mater. Chem. A, 2016, 4, 10691-10699.

27 X. Li, Z. Yang, Y. Fu, L. Qiao, D. Li, H. Yue and D. He, ACS Nano, 2015, 9, 1858-1867.

28 M. M. Mahmoud, Y. Cui, M. Rohde, C. Ziebert, G. Link and H. J. Seifert, Materials, 2016, 9, 506.
29 Q. Lin, X. Bu, C. Mao, X. Zhao, K. Sasan and P. Feng, J. Am. Chem. Soc., 2015, 137, 6184-6187.

30 F. Sun, K. Huang, Y. Liu, T. Gao, Y. Han and J. Zhong, Appl. Surf. Sci., 2013, 266, 300-305.

31 N. Nitta and G. Yushin, Part. Part. Syst. Charact., 2014, 31, 317-336.

32 M. Kruk and M. Jaroniec, Chem. Mater., 2001, 13, 3169-3183.

33 S. Kitagawa, R. Kitaura and S. I. Noro, Angew. Chem., 2004, 43, 2334-2375.

34 Y. Yu, C. Yang, Y. Jiang, X. Liu and X. Zhong, J. Mater. Chem. A, 2016, 4, 18711-18716.

35 Y. J. Cho, H. S. Im, Y. Myung, C. H. Kim, H. S. Kim, S. H. Back, Y. R. Lim, C. S. Jung, D. M. Jang, J. Park, E. H. Cha, S. H. Choo, M. S. Song and W. I. Cho, Chem. Commun., 2013, 49, 4661-4663.

36 S. B. Xia, S. W. Yu, L. F. Yao, F. S. Li, X. Li, F. X. Cheng, X. Shen, C. K. Sun, H. Guo and J. J. Liu, Electrochim. Acta, 2019, 296, 746-754. 